\title{
Impacts of Celebrity Fan Culture on Chinese Sports Stars in Contemporary China
}

\author{
Nan Wang ${ }^{1, *}$ \\ ${ }^{1}$ College of Landscape architecture \& Art design, Hunan Agricultural University, Changsha, 410000, China \\ ${ }^{*}$ Corresponding author. Email: wangnan@stu.hunau.edu.cn
}

\begin{abstract}
As the Tokyo Olympic Games and the 14th National Games of China were successfully held, the discussions about sports stars in the social media and social platforms have emerged in endlessly. It can be learned from the events being discussed that the occurrence and communication of such events show strong characteristics of celebrity fan culture. This paper discusses the impacts of celebrity fan culture on sports stars in China, and draws the conclusion that the celebrity fan culture, for sports stars, is both the opportunity and the challenge. On the one hand, it helps athletes to increase their visibility, improve their commercial value, and facilitate the promotion and development of sports. On the other hand, the athletes' mentality and training may be affected by the worship and discussion from celebrity fan clubs. Based on such phenomenon, this paper also gives some suggestions for the sports industry to increase its influence and realize "cross-circle" publicity by utilizing the celebrity fan culture. The sports stars should be aware of its advantages and disadvantages and stay focused on their sports career, the public should stay rational all the time, and the state and the society should strengthen their supervision on the platforms and publicize the right way to idolize stars.
\end{abstract}

Keywords: Celebrity, Fan Culture, Sports Stars.

\section{INTRODUCTION}

The celebrity fan club refers to the organization or group composed by a group of fans who spontaneously support or promote their idols. In recent years, with the rapid development of culture communication, the celebrity fan culture has expanded fast and gradually formed a system. As a lot of "celebrity fan clubs" composed of different fans put into a large amount of time, energy, funds etc., they have developed into an unpredictable force, and thus have become the practical and key support in the aspects of economy and image building for their "idol's" development and relevant activities [1]. Affected by the celebrity fan culture, the fans have developed the conventional thinking, such as helping their idols to get to the top of rankings, controlling comments, creating data etc. While getting together, they show unique characteristics of a celebrity fan club which makes people feel strong sense of identity and sense of belonging, so more and more youth groups are attracted to join in.

A significant field greatly affected by the celebrity fan culture is the sports circle. As announced by Sinan
Weibo, in the recent Tokyo Olympic Games, on the first day of the Olympic Games, the peak DAU reached 302 million. In the first weekend after the opening ceremony, these users posted 75.92 million blog articles discussing the Olympic Games, the accumulative interactions of netizens were up to 250 million times, and the page views of relevant topics exceeded 48.39 billion. Compared with the previous Rio Olympic Games in the same period, the interactions of netizens increased by $143 \%$ while the page views of relevant topics increased by $221 \%$. According to the statistics, the number of Weibo sports hot searches during the Olympic Games reached 3,462, 76 of which were hot searches. Among them, the reports of intense and fierce sports games bring people to focus on the competition fields, and the rising of new Olympic players and the persistence of old players were demonstrated. After concentrated reporting, the athletes become the focus of attention and the sports stars worshipped by the public. Relevant data showed the athletes were discussed by the users 8.67 million times on the Weibo platform. Among them, Yang Qian winning the first gold medal for China in Tokyo Olympic Games in the women's $10 \mathrm{~m}$ air rifle was mentioned 3.77 million times by the users, and the 
number of fans of her Weibo account increased from hundreds before the champion to millions. The highly exposed athletes have become the subjects affected by the celebrity fan culture.

\section{LITERATURE REVIEW}

As the celebrity fan culture becomes more and more influential, its great influence and available expansibility have been noticed by many cultures including the mainstream culture as well as by capitalists. Hall proposed the attitude of cultural opportunism utilization in the study of British subculture. Such attitude aimed to establish relationship with young people by accepting their entertainments and interests, then standardize the popular culture, and "try to create the 'jukebox' and rock and roll 'priest' on the altar" [2]. Relying on its own development, the celebrity fan culture has gradually collided and integrated with a number of circles. As a result, the phenomenon of celebrity fan clubs actively or passively appears in many circles. For instance, the emergency of celebrity fan clubs in the fund circle "makes financial services be close to the people, but it also causes many risks and uncertainties. Such irrational participation may result in chaotic internet phenomena taking place frequently, and develop to be hot spots of society" [3]. However, in many social events, "the celebrity fan culture enriched the mainstream culture, but it also brought the consciousness of "hegemony" inside into the mainstream culture, destroying the free market of opinions" [4]. In addition, the rapid development of celebrity fan culture has become a breeding ground for chaotic phenomena violating ethics and laws such as illegitimate child, Cyber Manhunt etc. Therefore, the development and communication of celebrity fan culture are worthy of attention.

B Smart4 deemed sports stars as a scare social resource. As for their value to the society, they can not only encourage and improve people's passion for life, but also play a significant role in the inheritance and guidance of social culture [5]. Some studies showed that the sports stars under the spotlight discover that their own value is far more than their sports field, and their value is more reflected in the commercial field [6]. As shown in relevant studies, more and more sports stars on active duty or retiring set foot in other industries, and they are more likely to be guests in variety entertainment programs or advertising spokespersons [7]. Undoubtedly, the communication mode in the celebrity fan culture will increase the value of athletes, multiply the influence of sports stars, and thus accelerate the development of sports, but the impact of celebrity fans' crazy and irrational support on athletes cannot be underestimated. Chinese Olympic Committee issued a statement on September 30 to make a stand against utilizing celebrity fan clubs to engage in profitable activities and call on fans to worship stars rationally. It can be seen that the impact of celebrity fan culture on sports stars cannot be neglected. For the benign development of sports stars under the influence of celebrity fan culture and the whole industry, the paper analyzes and summarizes the impacts of celebrity fan culture on sports stars, combines the policies of "Operation Qinglang" launched by Cyberspace Administration of China to give solutions for celebrity fan clubs, and thus provide reference suggestions for the cross-circle development of the whole sports industry.

\section{METHODOLOGY}

This paper studies a number of news events on the ranking list of Sina Weibo hot searches which were exposed by media and which aroused discussions in social network sites during the Games of the Tokyo Olympic and the 14th National Games of the People's Republic of China. Based on the qualitative research with the observation method, it analyses these events and the celebrity fan culture phenomenon shown in them, and studies the behaviours and motivation behind them as well as their possible impacts. It can be concluded from these events that the development of celebrity fan clubs has two different natures of impact on athletes. Firstly, the development of celebrity fan clubs has a positive impact on athletes. People notice that the commercial map of athletes such as Yang Qian, Su Bingtian etc. are expanding quickly recently, because the support from their fan clubs has strengthened their popularity, influence as well as their sense of honour and belonging. Furthermore, it is a great help for cross-circle promotion of sports culture. Secondly, the development of celebrity fan clubs has a negative impact. The celebrity fan club support and publicity activities, the black industry chain in the celebrity fan clubs, and the fans' unreasonable star worship have seriously affected the athletes' life, training and right of reputation.

\section{DISCUSSION}

It is reasonable to talk about the positive impact of celebrity fan culture on sports stars. Zhang Qin, a sports marketing specialist and the founder of Key-solution Sports Consulting Co., Ltd. said, "generally, commercial enterprises assess the brand value of sports stars from three dimensions, and the most core one is their competitive value, including their influence in their field, the influence of their achievement etc. The second one is their social value, including their cross-circle ability beyond the arena, their personal story etc. The third one is their value in the aspect of commercial application, including their degree of freedom, expandable commercial space" [8]. Driven by social economy and social media, the celebrity fan culture, to a 
great extent, increases the social value and commercial application value of sports stars.

After the Olympic Games, a number of social platforms cooperated with the athletes, for instance, asking them to share topics such as \#the athletes' quarantine dairy\# and \#keep fit at home with the athletes\#, so that they could strengthen their own labels and personality construction, improve their influence, draw the attention of brand owners, and publicize their sports. In this way, it can not only create the atmosphere for nationwide fitness, but also drive the commercial development of sports stars.

The negative impact of celebrity fan culture on sports stars is also obvious. After the National Games, Wang Shun, a swimmer, was forced by his fans to wear a hat at the airport. After Wang Shun took off the hat, his fans still asked him to put on with an aggressive attitude. Fan Zhendong, a Ping-Pong player, also encountered similar situation. His fans approached him crazily, so he who didn't have social media accounts had to make an announcement through the Weibo account of his fan club, and earnestly ask his fans to worship stars rationally. Crazy and aimless star worship has been existing for a long time, but more in the circle of entertainment stars in the past. With the cross-circle development of sports industry, in the face of the fierce market competition, to attract audiences, the sports news has started to be presented in an entertainment way, and it has gradually developed to be a trend [9]. As more young people join in the sports trend due to such change, but the large group of fans newly increased may not be sports participants, which is also the key reason why sports stars are affected by the celebrity fan culture.

\subsection{The impact of coupling on the athletes}

Yang Qian, the champion of women's single $10 \mathrm{~m}$ air rifle and mixed 10metre air rifle in the Tokyo Olympic Games, is a young athlete born in 2000s. After the Chinese team won its first gold model in the Olympic Games on July 24, she drew many people's attention. In the ranking list of top hot searches, five of six top hot searches were about her, and the key words such as "Tsinghua University", "scholar-lord gunner", "finger heart", "pearl manicure" etc. became hot topics related to the athlete. However, after she got the mixed team champion with Yang Hao, many fans shipped them because of the touching moment that they put on the medal for each other on the podium as well as their tacit cooperation on the field. Their daily communication and training became the evidence that people felt them well matched. For a time, their cp fans attacked and occupied the comment sections and topic pages of the two athletes, and crazily spread the traces that they are together on the internet. Instead of focusing on the performance of athletes on the field, many audiences were wild about observing their private life, which caused big troubles for their training and life.

"CP" is the abbreviation of the verb "coupling", and refers that the behaviour that audiences ship fictional people [10]. "Everything can be coupled". The "coupling culture" is a branch of the celebrity fan subculture. It mainly features over interpretation and fictitious collage of text or role relationship, and then publicize and gather them in multi-dimensional communities of the cyberspace with new media technology. CP fans may ship Lord Voldemort and Lin Daiyu, or any combination to enjoy the joy of romance fantasy. In recent years, affected by the crazy promotion of bl and bg screen couples in the entertainment circle of China, coupling is very popular in current entertainment circle of China.

However, the normal friendly communications between Yang Qian and Yang Haoran are excessively magnified by the $\mathrm{cp}$ fans and analysed as the intimate love between them, and their good interaction and cooperation become the evidence of a good match. As people always yearn for the sweet lovers fighting side by side, for them, the fans' borderless publicity is tempting but somewhat deceptive. Many people who don't know the truth may think Yang Qian and Yang Haoran are a couple. It is very awkward for teammates who always have trainings together. Two athletes expressed their attitude in their Weibo. Yang Haoran said, "people who are wild about coupling, please stop. If you continue, my colleagues may misunderstand. My brain is buzzing." Yang Qian said, "that's impossible, sir. You even said Phoenix Legend was a couple." In addition to this, Yang Qian also said in her live broadcast that she hoped no people would take the coupling thing seriously.

In the entertainment circle or for people who wanted to be exposed or draw attentions, it may be a good way to obtain benefits, but its impact on athletes needs to be analysed dialectically. For instance, for the Olympic couple, Zou Kai who won five gold medals and his wife Zhou Jie, a gymnast, participated in Viva La Romance. They support and love each other, and their athlete-style romance shown in the program touched a large number of audiences. The audiences' appreciation and discussions of their romance not only increased the program audience rating, but also helped the two athletes realize the cross-circle influence and raise their profiles. However, for Yang Qian and Yang Haoran, the partners on active service, the fans made groundless accusations to ship them, and even "directly asked them about it". Therefore, it is inevitable to cause adverse impact and harm to them, and affect their normal training, and even their rest. 


\subsection{The impact of extreme public opinions on athletes}

Wang Luyao who participated in the $10 \mathrm{~m}$ air rifle in the Tokyo Olympic Games together with Yang Qian suffered a setback and didn't enter the finals. After the competition, she tweeted "I am sorry. It's a shame. I admit I am frightened. See you three years later" on the social platform, and posted a selfie at the same time. Soon after it was posted, Wang Luyao was attacked by cyber violence. Some people accused her of not reflecting on the competition after the setback, but acting like an internet celebrity to post a selfie; some people were unsatisfied with the text, and thought that being frightened insulted the sportsmanship. Yang Jian, a diver, won the silver medal in the $10 \mathrm{~m}$ platform diving final, narrowly fell behind Cao Yuan, his teammate, but because he did not congratulate his teammate after the competition, many netizens accused him of lacking tolerance and envying his teammate.

Due to the extreme public opinions in the celebrity fan circles, athletes are attached by cyber violence, so is their family. Quan Hongchan, the 14-year-old diving champion, is from a poor family. Her mother suffers from disability, and only her father has the ability to make money. As described in a report, Quan's father liked to smoke. One time when he went out to sell vegetables, as the business was bad, he threw away the unsold vegetables to save fuel. After seeing it, many fans thought Quan's father was irresponsible and wasted the painstaking effort of Quan's mother. The netizens didn't consider the realistic factors. When they didn't see what they wanted to see, they would feel unsatisfied, and even thought Quan's father would ride on the wave of his daughter's popularity, and would hurt his daughter. For this reason, Quan Hongchan's father was reviled on the internet.

Aactually people are not strange to such phenomena. The cyber violence arising out of extreme public opinions almost happens every day, and especially in the celebrity fan clubs, upvoting, downvoting and accusing are a part of everyday life. Due to the special characteristics of internet communication, anyone entering into internet can speak out freely with a virtual identity. There are rational and constructive ideas and opinions among such comments, but there is also irrational emotional catharsis [11]. The phenomenon of abusing each other is serious in the celebrity fan clubs. On the one hand, the reason is that thanks to the developed social media in the mobile internet era and the platform mechanism, the celebrity fan clubs are easy to organize; on the other hand, in the entertainment circle, internet traffic means benefits. Some social platforms and marketing accounts may cooperate with actors to pursue internet traffic without limit, so they are pleased to see and even induce people to create data, and deliberately make topics and provoke the celebrity fan clubs to abuse each other [12]. However, as a matter of fact, the sports circle and the entertainment circle are totally different. The sports circle lays more emphasis on achievements rather than popularity, so hype is not required, and the athletes shouldn't descend to be a tool for platforms to get more traffic. The reason why Wang Luyao and Yang Jian were attached by cyber violence is partially because people treat them as stars, and thus have stricter requirements on them. As for public opinions on Quan Hongchan's father, people should be more careful, and not be utilized by media trying to gain traffic with fragmented information. It should be noted that sports stars are not stars with huge fan bases. They are essentially athletes, so they don't need expression management, and also have the right to express their feelings. The public shouldn't be too hard on them, and pay too much attention to their private life rather than their competitions.

It is also necessary to talk about how to avoid negative impact, and how to improve the sports star fan economy. The development of celebrity fan clubs can help the development of sports undertakings and the increase of sports stars' value, but be faced with the development of celebrity fan clubs, sports stars and their management teams should keep a clear head, and the fans should stay rational.

Sports stars and their teams should be stay vigilant all the time, and balance their trainings, competitions and entertainment activities while breaking through the circle to realize their commercial value. Athletes should stay rational in the face of the "unconditional support" slogan of their fans, accept external criticism, and strive to enhance their own strength. Meanwhile, their teams should have a long-term plan to protect the athletes' commercial value. While merchants keep coming in, they may use the experience of the commercial development mode of International Olympic Committee, TOP Plan. Strictly restrict the categories in the first place, and while selecting commercial cooperation partners, conduct meticulous investigations to have a good understanding on their background [13].

The fans should respond to the "Operation Qinglang" policy and the statement of China Olympic Committee, treat sports stars with a correct attitude, recognize advantages and disadvantages, not mechanically apply the discourse pattern of "celebrity fan culture" into the sports circle, lay more emphasis on competition fields and sports sprit, worship stars rationally, and not engage in any activities harming themselves or the athletes.

The state and the society need to call on the public to worship stars rationally, further make administrative departments, industrial associations, platforms etc. into full play, and further regulate the chain of celebrity fan clubs in sports industry; on the other hand, strengthen publicity and education through which, more young people will realize the real sports spirit, develop the 
right way and attitude of star worship, and avoid aggressive behaviours.

\section{CONCLUSION}

To sum up, the celebrity fan culture has both advantages and disadvantages for sports stars. Firstly,it contributes to the cross-circle development of sports culture.Let more people know and love sports, and publicize the positive sports spirit of faster, higher and stronger fearing difficulties to the society.Secondly it can helps sports stars to increase their popularity and enhance their commercial value, increase their income and improve their reputation. But due to the characteristics of celebrity fan culture, it also causes some troubles in the aspects such as public opinions, life and even health of the athletes. That really affect their training and competition. As the "Sports for All" policy is promoted and the 2022 Olympic Winter Games is about to be held in China.In the current new media communication mode and the promotion mode of people accepting fragmented information, the celebrity fan culture shall bring greater impact. In the future, the excellent legendary athletes with distinctive national features such as Su Bingtian, Yang Qian. emerging victorious in the Tokyo Olympic Games are expected to be phenomenon-level superstars. They can enhance their own commercial value and contribute to the spread of sports spirit. However at the same time, they will also face the impact of life under high attention, and even lose their goal and fighting spirit. Therefore, in the face of opportunities and challenges brought by the development of celebrity fan clubs, the public、 the state the society and the athletes should stay rational, while the fans should support their favourite sports stars in a proper way and with a right attitude and should keep a suitable distance from sports stars. Moreover, fans should absorb their sports spirit to live a more healthy and optimistic life; While Athletes' teams and relevant departments should abide by their responsibilities, strengthen the guidance of fans and avoid public opinion and activities harmful to athletes, athletes should always keep their original intention in mind, accept both encouragement and criticism with an open mind. Besides they need to play seriously and live up to the expectations of the public.

\section{REFERENCES}

[1] Zhang Yiwu, Reflection on "Celebrity Fan Culture", Chinese literature and art review, (2021).

[2] $\mathrm{Hu}$ Jiangfeng, Subculture style: Resistance and incorporation[D]. Capital Normal University, (2007).

[3] Xiao pan, The development of celebrity fan clubs on fund: Irrational Carnival in the era of network communication, New media research, (2021).
[4] Liu Jiangdan,"Hegemony" of Internet discourse space - Characteristics of lunch circle culture in Network Environment, (2021).

[5] B Smart, The Sport Star: Modern Sport and The Cultural Economy of sporting Celebrity [J]. Contemporary Sociology, (2005).

[6] Yu Nengguan, Research on the commercial value development of Chinese sports stars, (2017).

[7] Xu hui, Research on cross-border phenomenon of sports stars, Research on communication power, (2018).

[8] Li Yuan, How far is the sports star from the commercial value IP, China business daily, (2021).

[9] Liu Yong, On the evolution and causes of entertainment of sports news in China[D]. Hefei. Anhui University, (2010).

[10] Shao Yanjun, Wall breaking book: key words of network culture[M]. Beijing: Sanlian Bookstore, (2018).

[11] Chen Ming, Current situation and guidance of Internet public opinion in China[J]. Outlook Newsweek, (2012).

[12] Wang Guoliang, Rectification of "mutual tearing of celebrity fan culture", Anhui Daily, (2020).

[13] Li Yuan, How far is the sports star from the commercial value IP, China business daily, (2021). 